\title{
Role of Adiponectin in Cardiovascular Protection
}

\author{
Mamoru Nanasato, MD; Toyoaki Murohara, MD*
}

A

therosclerosis is a pathological injury-to-response process that is initiated by early inflammatory responses of vascular endothelial cells. Endothelial inflammation is characterized by decreased nitric oxide (NO) formation, platelet adherence to endothelium, monocyte adhesion and migration into the neointima lesion, followed by transformation of macrophages into foam cells. Subsequently, oxidized low-density lipoproteins accumulate in the atherosclerotic plaques forming lipid or necrotic core. Vascular smooth muscle cell (VSMC) proliferation and migration, and extracellular matrix (ECM) formation/degradation also play important roles in the development of plaque formation and destabilization. During this process, various cytokines/chemokines, reactive oxygen free radicals and various proteases released from macrophages, platelets and VSMCs contribute to the progression of complicated atherosclerosis.

\section{Article p 552}

Recently, adipocytes are believed as not only simple energy-storing cells but also function as active secretory cells. Adipocytes release several cytokines including tumor necrosis factor (TNF)- $\alpha$, leptin, interleukins, angiotensinogen and adiponectin. The majority of these adipokines causes inflammation in the arterial wall, resulting in endothelial dysfunction, macrophage accumulation and VSMC proliferation/ migration. These adipokines are believed to play an important role in the progression of atherosclerosis.

In contrast to the inflammatory adipokines, adiponectin has been reported to increase insulin sensitivity and to suppress atherosclerosis. Adiponectin is a $30-\mathrm{kDa}$ protein that contains an N-terminal collagenous domain and C-terminal globular domain, and the most abundant adipokine secreted from adipocytes. The plasma concentrations of adiponectin decreased in patients with obesity, type 2 diabetes mellitus, hypertension, and metabolic syndrome. ${ }^{1}$ Adiponectin suppresses endothelial adhesion molecule expression, which interferes with monocyte adhesion/migration and transition to foam cells. Adiponectin also suppresses the proliferation of VSMCs. In fact, neointimal thickning due to arterial injury is increased in adiponetin-knockout mice compared to wild-type animals. These data collectively suggest that adiponectin works to prevent atherosclerosis. Interestingly, there was a significant difference of plasma adiponectin concentrations between the longevity and non-longevity districts in Japan. ${ }^{2}$ Low plasma adiponectin concentrations were associated with increased prevalence of myocardial infarction and cardiovascular mor- tality. ${ }^{3,4}$

In this issue of the Journal, Li and co-workers reported the effects of adiponectin on stability of pre-existing plaques. They have identified a novel mechanism by which adiponectin stimulates the expression of prolyl 4-hydroxylase $(\mathrm{P} 4 \mathrm{H})$ that induces extracellular matrix synthesis. ${ }^{5}$ They identified that the administration of adiponectin stabilized plaques as documented by increased fibrous cap and less incidence of intraplaque bleeding. Although the plaque volume was not changed, the thickness of fibrous cap, cap-to-core ratio and VSMC contents were all increased by adiponectin administration. The further search for enzymatic factors revealed that the $\mathrm{P} 4 \mathrm{H}$ was significantly increased by administration of adiponectin, resulting in the production of type I and III collagens. The authors concluded that adiponectin increases collagen production by stimulating the expression of $\mathrm{P} 4 \mathrm{H}$, which may play a major role in the development of a thick fibrous cap in pre-existing advanced atherosclerotic plaque.

The authors' observation that adiponectin induces the expression of $\mathrm{P} 4 \mathrm{H}$, and that adiponectin increases collagen contents of plaque are important findings from a therapeutic point of view. Adiponectin is negatively correlated with the ratio of matrix metalloproteinase (MMP)-9/tissue inhibitors of metalloproteinases (TIMP)-1. ${ }^{6}$ MMPs are well-known key enzymes that degrade ECMs. MMP-9 destabilizes advanced plaques by degrading ECM, while TIMP-1 counteracts this effect. Administration of hydroxymethylglutaryl coenzyme A reductase inhibitors (statins) decreased MMP-1, -2, -3, -7, and -9 expression, ${ }^{7}$ glycoprotein thrombospondin-1 expression, gelatinolytic activity, endothelial adhesion molecules expression, and leukocyte infiltration. In contrast, it is controversial whether statins increase expression of plaque-stabilizing ECM such as type I collagen. ${ }^{8}$ As the lipid-lowering therapy with a statin for 9 months after the onset of acute myocardial infarction significantly increased the fibrous-cap thickness in patients with hyperlipidemia, ${ }^{9}$ it might protect fibrous caps against degradation by MMPs and, thus stabilized plaques.

ECM components determine the plaque stability and vulnerability to rupture. Collagen is the main constituents of the fibrous cap in atheroma and one of the most metabolically active ECMs with at least 39 subtypes. Types I and III collagens are the ones most commonly found in the arterial wall. The intracellular modifications to produce collagen require 5 specific enzymes, including 3 collagen hydroxylases and 2 collagen glycosyltransferases. The synthesis of all known types of collagens depends on $\mathrm{P} 4 \mathrm{H},{ }^{10}$ one of the key intra-

The opinions expressed in this article are not necessarily those of the editors or of the Japanese Circulation Society.

Received January 15, 2010; accepted January 17, 2010; released online February 9, 2010

Cardiovascular Center, Nagoya Daini Red Cross Hospital, *Department of Cardiology, Nagoya University Graduate School of Medicine, Nagoya, Japan

Mailing address: Mamoru Nanasato, MD, Cardiovascular Center, Nagoya Daini Red Cross Hospital, 2-9 Myouken-cho, Showa-ku,

Nagoya 466-8650, Japan. E-mail: nana@ nagoya2.jrc.or.jp

ISSN-1346-9843 doi:10.1253/circj.CJ-10-0036

All rights are reserved to the Japanese Circulation Society. For permissions, please e-mail: cj@j-circ.or.jp 
cellular enzymes. Although relatively little data is available for factors affecting $\mathrm{P} 4 \mathrm{H}$ expression and activity, $\mathrm{P} 4 \mathrm{H} \alpha(\mathrm{I})$, an active subunit that catalyzes the oxygen-dependent hydroxylation of proline residue in procollagen, increased 2- to 3fold after an 8-h exposure to hypoxia at both transcriptional and post-transcriptional levels. ${ }^{11} \mathrm{P} 4 \mathrm{H}$ expression is also regulated by NO, TNF- $\alpha$, transforming growth factor- $\beta$, insulinlike growth factor-1, $\beta$ fibroblast growth factor, cytokines, and even cigarette smoking as well. ${ }^{12}$

It has been reported that the anti-atherogenic effect of adiponectin was in part mediated by its regulatory ability on collagen synthesis, ${ }^{13}$ but precise molecular mechanism was unknown. In the current study by Li and co-workers, they newly identified that adiponectin is another player for the regulation of $\mathrm{P} 4 \mathrm{H}$ expression. In the advanced stage of atherosclerosis, the beneficial action of adiponectin is related to the stabilization of plaques rather than the inhibition of further atherosclerotic burden. The findings by $\mathrm{Li}$ and coworkers provide additional novel insight into the mechanisms of cardiovascular protection by adiponectin in patients with advanced atherosclerosis.

\section{References}

1. Sakamoto K, Sakamoto T, Ogawa H. Effects of metabolic risk factors on production of plasminogen activator inhibitor-1 and adiponectin by adipocytes. Circ J 2008; 72: 844-846.

2. Mori I, Ishizuka T, Morita H, Matsumoto M, Uno Y, Kajita K, et al. Comparison of biochemical data, blood pressure and physical activity between longevity and non-longevity districts in Japan. Circ $J$ 2008; 72: $1680-1684$

3. Pischon T, Girman CJ, Hotamisligil GS, Rifai N, Hu FB, Rimm EB. Plasma adiponectin levels and risk of myocardial infarction in men. JAMA 2004; 291: 1730-1737.

4. Wannamethee SG, Whincup PH, Lennon L, Sattar N. Circulating adiponectin levels and mortality in elderly men with and without cardiovascular disease and heart failure. Arch Intern Med 2007; 167: $1510-1517$.

5. Li L, Cai XJ, Feng M, Rong YY, Zhang Y, Zhang M. Effect of adiponectin overexpression on stability of preexisting plaques by inducing prolyl-4-hydroxylase expression. Circ J 2010; 74: $552-$ 559.

6. Cheng M, Hashmi S, Mao X, Zeng QT. Relationships of adiponectin and matrix metalloproteinase- 9 to tissue inhibitor of metalloproteinase-1 ratio with coronary plaque morphology in patients with acute coronary syndrome. Can J Cardiol 2008; 24: 385-390.

7. Luan Z, Chase AJ, Newby AC. Statins inhibit secretion of metalloproteinases-1, -2, -3, and -9 from vascular smooth muscle cells and macrophages. Arterioscler Thromb Vasc Biol 2003; 23: 769-775.

8. Riessen R, Axel DI, Fenchel M, Herzog UU, Rossmann H, Karsch KR. Effect of HMG-CoA reductase inhibitors on extracellular matrix expression in human vascular smooth muscle cells. Basic Res Cardiol 1999; 94: 322-332.

9. Takarada S, Imanishi $\mathrm{T}$, Kubo $\mathrm{T}$, Tanimoto $\mathrm{T}$, Kitabata $\mathrm{H}$, Nakamura N, et al. Effect of statin therapy on coronary fibrous-cap thickness in patients with acute coronary syndrome: Assessment by optical coherence tomography study. Atherosclerosis 2009; 202: 491-497.

10. Kivirikko KI, Helaakoski T, Tasanen K, Vuori K, Myllylä R, Parkkonen T, et al. Molecular biology of prolyl 4-hydroxylase. Ann N Y Acad Sci 1990; 580: $132-142$

11. Takahashi Y, Takahashi S, Shiga Y, Yoshimi T, Miura T. Hypoxic induction of prolyl 4-hydroxylase $\alpha$ (I) in cultured cells. J Biol Chem 2000; 275: 14139-14146.

12. Zhang C, Zhang MX, Shen YH, Burks JK, Zhang Y, Wang J, et al. TNF- $\alpha$ suppresses prolyl-4-hydroxylase $\alpha 1$ expression via the ASK1-JNK-NonO pathway. Arterioscler Thromb Vasc Biol 2007; 27: $1760-1767$

13. Wolk R, Berger P, Lennon RJ, Brilakis ES, Davison DE, Somers VK. Association between plasma adiponectin levels and unstable coronary syndromes. Eur Heart J 2007; 28: 292-298. 